\title{
Pembangunan Aplikasi Web Event Menggunakan Framework Spring Boot di PT XYZ
}

\author{
Willyam Chrisna Umbu Dagha*1, Yerymia Alfa Susetyo ${ }^{2}$ \\ ${ }^{1,2} \mathrm{Jl}$. Diponegoro 52-60, Salatiga 50711, Indonesia \\ ${ }^{3}$ Jurusan Teknik Informatika, FTI UKSW, Salatiga

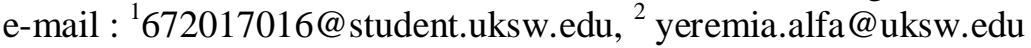

\begin{abstract}
Abstrak
PT. XYZ merupakan perusahaan yang bergerak dalam pengembangan teknologi informasi, selain bergerak dalam pengembangan teknologi informasi PT. XYZ juga aktif bergerak dalam memberikan edukasi kepada mahasiswa, dosen dan masyarakat dalam bentuk event-event pembelajaran yang diadakan oleh PT. XYZ. Setelah berjalannya waktu muncul beberapa kendala yang timbul, dikarenakan pendaftaran melalui formulir pendaftaran online menyebabkan pendaftar harus melakukan pengisian data lengkap berulang kali jika mengikuti event yang berbeda dan informasi event sangat terbatas karena hanya disosialisasikan melalui Instagram. Hal tersebut membuat ketidaknyamanan pada sisi pendaftar sehingga bisa mengurangi antusias pendaftaran event. Penelitian ini bertujuan untuk membangun aplikasi berupa aplikasi web yang bertujuan untuk mengelola informasi event secara lengkap dan memudahkan pendaftar melakukan pendaftaran. Dalam pengembangan sistem ini menggunakan Framework Spring Boot dengan bahasa pemrograman yang digunakan adalah bahasa pemrograman Java. Spring Boot sangat memudahkan dalam pengembangan sistem karena bersifat open source, dokumentasi yang lengkap, dan modul yang cukup lengkap seperti JDBC, ORM, Servlet, dll. Spring Boot sendiri mendukung pembuatan aplikasi berbasis restfull web Service sehingga memungkinkan programer untuk mengkombinasikan dengan bahasa pemrograman yang lain. Hasil dari penelitian ini sendiri adalah sebuah perancangan dari sebuah web yang kemudian diimplementasikan menggunakan bahasa pemrograman java dan menggunakan Framework Spring Boot sebagai kerangka kerja.
\end{abstract}

Kata kunci-Web Event, Spring Boot, Java

\begin{abstract}
PT. XYZ is a company engaged in the development of information technology. In addition to engaging in the development of information technology PT. XYZ is also actively engaged in providing education to students, lecturers and the public in the form of learning events held by PT. XYZ. After the passage of time, several problems arise, because registration through online registration form causes the registrant must fill in complete data repeatedly if participating in different events and information about the event is very limited because it is only socialized through Instagram. This creates inconvenience on the registrant's side, so that it can reduce enthusiastic event registration. This study aims to build applications in the form of a web application that aims to manage complete event information and facilitate the applicants to register. This system was developed using the Spring Boot Framework with the Java programming language. Spring Boot greatly facilitate the development of the system because it is open source, complete documentation, and complete modules such as JDBC, ORM, Servlet, etc. Spring Boot itself supports the creation of applications based on restfull web service so that it allows programmers to combine it with other programming languages. The result of this research is a web design which is then implemented using the Java programming language and using the Spring Boot Framework as a framework.
\end{abstract}

Keywords-Web Event, Spring Boot, Java 


\section{PENDAHULUAN}

PT XYZ adalah salah satu perusahaan teknologi yang aktif mengadakan event seminar dan kegiatan yang edukatif, khususnya dalam bidang Teknologi informasi (TI). Semua informasi event yang diselenggarakan PT XYZ bisa dilihat pada instagram resmi PT XYZ. Event ini dapat diikuti oleh mahasiswa, dosen, fresh graduate, dan siapapun yang tertarik dalam bidang IT.

PT XYZ sendiri selalu mengadakan pendaftaran seminggu sebelum acara dimulai. Pendaftaran dilakukan dengan cara menyebarkan informasi dan tautan pendaftaran yang mengarah ke formulir pendaftaran online. Namun, terdapat beberapa masalah yang timbul, seperti pendaftar harus memasukkan data diri berulang kali jika ingin mengikuti event berbeda. Cara pendaftaran ini dinilai kurang efisien, karena cukup memakan waktu. Selain itu, pada formulir pendaftaran online tidak terdapat informasi ketersediaan status acara dan integrasi aplikasi ke alamat email sehingga panitia harus melakukan kegiatan ekstra untuk mengingatkan peserta. Untuk mengatasi masalah tersebut, dibutuhkan aplikasi yang bisa mengelola acara acara event dengan baik.

Penggunaan aplikasi berbasis web dapat menjadi solusi bagi masalah tersebut. Aplikasi web sendiri bisa diakses di berbagai sistem operasi dan bisa diakses hampir di semua perangkat. Pembangunan web merupakan proses yang cukup kompleks karena melibatkan aliran data yang cukup banyak dan penyusunan kode program yang cukup kompleks untuk menangani itu penggunaan bahasa pemrograman Java dan Framework Spring Boot sangat membantu. Java dipilih daripada bahasa pemrograman lain karena memiliki sifat fleksibel yang menjadikanya bahasa pemrograman yang mudah dikembangkan sesuai kebutuhan, bersifat multiplatform yang menjadikan bahasa pemrograman Java mudah digunakan di berbagai jenis sistem operasi [1][2][3]. Java terus menerus dikembangkan dan ditambah dengan banyak fitur yang bisa digunakan para programer untuk membuat program aplikasi yang stabil dan aman sesuai dengan kebutuhan saat ini. Penggunaan framework Java yaitu Spring Boot semakin memudah pembangunan web karena Spring Boot termasuk framework yang cukup ringan untuk digunakan, bersifat open source, memiliki cukup banyak modul - modul yang bisa digunakan untuk membantu pekerjaan pengembang aplikasi dan Spring Boot sendiri bisa dikombinasikan dengan bahasa pemrograman lain karena Spring Boot mendukung pembuatan aplikasi berbasis restfull web Service. Spring Boot memungkinkan memakai modul - modul yang kita butuhkan saja sehingga projek yang dikerjakan menjadi lebih ringan [4][5].

Dengan masalah yang terjadi bisa disimpulkan dibutuhkannya aplikasi web event yang dapat mengelola setiap event PT XYZ dengan baik. Aplikasi Web Event ini akan dibangun menggunakan Framework Spring Boot. Dengan adanya aplikasi web event ini para peserta bisa mencari event yang diminati dengan mudah, ketersediaan informasi yang lengkap pada setiap event dan peserta tidak perlu mengisi data diri berulang kali saat mendaftar karena sudah memiliki akun yang mana sudah memuat informasi data diri dari peserta, peserta hanya perlu registrasi pada setiap event yang ingin diikuti, pada setiap event juga memiliki informasi yang lengkap sehingga memudahkan para peserta untuk memilih event yang mereka minati dan admin bisa mengelola informasi setia event dengan mudah.

\section{METODE PENELITIAN}

\subsection{Tinjauan Pustaka}

Penelitian yang berjudul "Java Spring Boot Rest Web Service Integration with Java Artificial Intelligence Weka Framework". Penelitian yang dilakukan membahas bagaimana Framework Spring Boot diintegrasikan dengan Java Artificial Intelligence Weka untuk 
membangun aplikasi prediksi cuaca. Dari penelitian tersebut disimpulkan Spring Boot memberikan pengalaman pembangunan aplikasi yang jauh lebih cepat, dapat diakses secara luas untuk semua pengembangan Spring dan menyediakan berbagai fitur non-fungsional yang umum untuk proyek kelas besar (misalnya server tertanam, keamanan, pemeriksaan kesehatan, konfigurasi eksternal) [6]. Karena kesimpulan yang didapatkan pada penelitian tersebut, peneliti hendak menerapkan Framework Spring Boot untuk pembuatan aplikasi web event.

Pada penelitian yang berjudul "Rancang Bangun Web Service - JSON Menggunakan Kombinasi Spring dan MyBatis Framework dalam lingkungan Java Platform". Pada penelitian ini membahas tentang pengujian performa kombinasi Spring Boot dengan MyBatis dengan serangkaian pengujian menggunakan data dummy dengan jumlah 100.000 baris data serta uji performa data loading dengan cara increment load terhadap url data Json. Penelitian ini menghasilkan Perpaduan Spring Framework 4.0.1 dan MyBatis menghasilkan performa yang cukup bagus dilihat dari rata-rata kecepatan tertinggi dapat dilihat kecepatan tertinggi akses dapat dilihat pada scenario satu hit 100 pada spesimen dua dengan kecepatan 954 milidetik dan Untuk rata - rata kecepatan akses paling rendah dapat dilihat pada scenario satu hit 500 pada spesimen 1 dengan kecepatan 2.823 milidetik [7]. Dari penelitian tersebut peneliti hendak menerapkan teknologi Framework Spring karena memiliki performa yang cukup bagus untuk mengolah data dan bisa dikombinasikan dengan framework yang lain tanpa mengurangi performa dari Spring Boot.

Pada penelitian yang berjudul "Analisis Model View Controller (MVC) Pada Bahasa PHP". Penelitian ini membahas tentang implementasi model view controller pada bahasa pemrograman PHP. Penelitian ini mengungkapkan penerapan MVC pada bahasa pemrograman PHP menghasilkan performa dalam indikator performa baik dan performa yang cukup optimal dalam penggunaan reusable [8]. Karena penerapan arsitektur MVC pada penelitian ini menghasilkan performa yang cukup bagus maka peneliti akan menerapkan arsitektur MVC pada penelitian yang akan dilakukan, yang membedakan penelitian akan menggunakan bahasa pemrograman Java dengan Framework Spring Boot bukan menggunakan PHP.

Pada penelitian yang berjudul "Pengembangan Aplikasi Manajemen Event Berbasis $W e b$ ". Penelitian ini membahas tentang pembangunan aplikasi manajemen event berbasis web di Fakultas Ilmu Administrasi Universitas Brawijaya Malang untuk memecahkan masalah dalam pengajuan event. Penelitian ini menghasilkan aplikasi yang bisa mendaftar event secara online, pengecekan ketersediaan venue, pencatatan data peminjaman venue yang lebih efisien dan mempersingkat sistem administratif yang manual menjadi berbasis online [9]. Karena pembangunan aplikasi web event menjadikan pendaftaran dan pengelolaan event menjadi lebih efisien dan menjadi lebih cepat sehingga peneliti ingin membangun aplikasi pada PT. XYZ untuk memecahkan masalah yang terjadi di PT.XYZ yang membedakan penelitian ini dengan penelitian yang akan dilakukan terletak pada teknologi yang digunakan. Pada penelitian ini pembangunan aplikasi ini menggunakan Node.js dan Express.js serta Semantic UI sedangkan penelitian yang akan dilakukan peneliti menggunakan bahasa pemrograman Java dan Framework Spring Boot.

\subsection{Metodologi Penelitian}

Dalam pembangunan aplikasi web event dilakukan dengan perencanan pembangunan menggunakan metode Waterfall, berikut beberapa tahapan yang dikerjakan seperti Analisis kebutuhan, desain sistem, penulisan kode program dan penulisan laporan seperti pada Gambar 1 . 


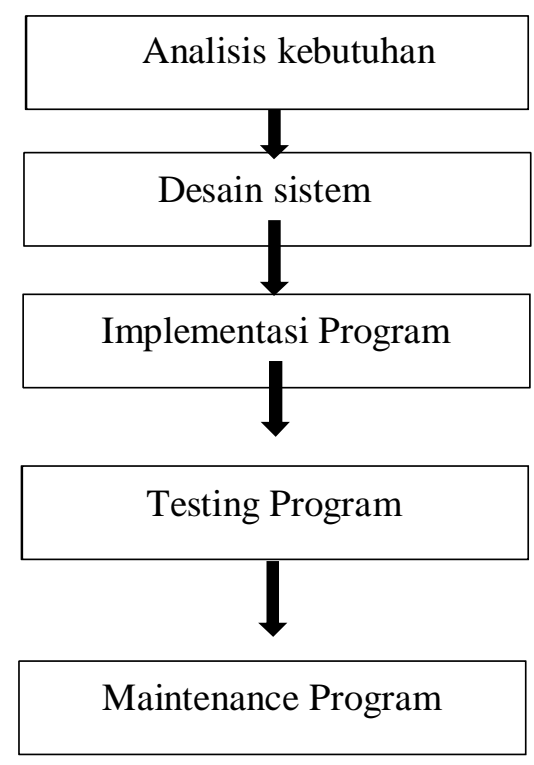

Gambar 1. Metode Penelitian

Berdasarkan Gambar 1 dijelaskan tiap proses yang dilakukan dalam penelitian, yang pertama pengumpulan dan analisis data. Pengumpulan dan analisis data dilakukan saat bertemu dan berdiskusi dengan mentor yang berada di PT XYZ agar mendapatkan informasi yang lengkap dan solusi yang terbaik. Salah satu contoh informasi yang didapatkan setelah pengumpulan dan analisis data adalah pengiriman konfirmasi pendaftaran berupa email secara otomatis saat peserta sudah mendaftar event. Kemudian setelah mendapatkan data dan analisis data, dilakukan tahap kedua yaitu desain sistem aplikasi web event yang meliputi BPMN, Use Case dan Kelas Diagram. Berikutnya setelah melakukan desain sistem dilakukan tahap ketiga berupa implementasi program, pada tahap ini dilakukan pembuatan aplikasi yang dirancang dengan bahasa pemrograman Java dengan Framework Spring Boot. Tahap keempat melakukan testing, metode yang digunakan untuk testing menggunakan metode Black Box. Tehap kelima maintenance akan dilakukan jika ditemukan kesalahan pada sistem.

\section{HASIL DAN PEMBAHASAN}

Pada bab hasil dan pembahasan dibagi menjadi beberapa topik pembahasan, diawali dengan perancangan sistem yang mencakup perancangan Business Process Modelling Notation (BPMN) kemudian perancangan Use Case dan perancangan Class Diagram. Setelah perancangan sistem dilanjut implementasi yang mencakup pembuatan projek, konfigurasi pada aplikasi properties, pembuatan kode program menggunakan bahasa pemrograman Java menggunakan konsep MVC dan implementasi Interface.

\subsection{Process Modelling Notation (BPMN)}

Business Process Modelling Notation (BPMN) adalah sebuah standar untuk memodelkan proses bisnis yang menyediakan notasi grafis dalam menjelaskan sebuah proses bisnis [10]. 


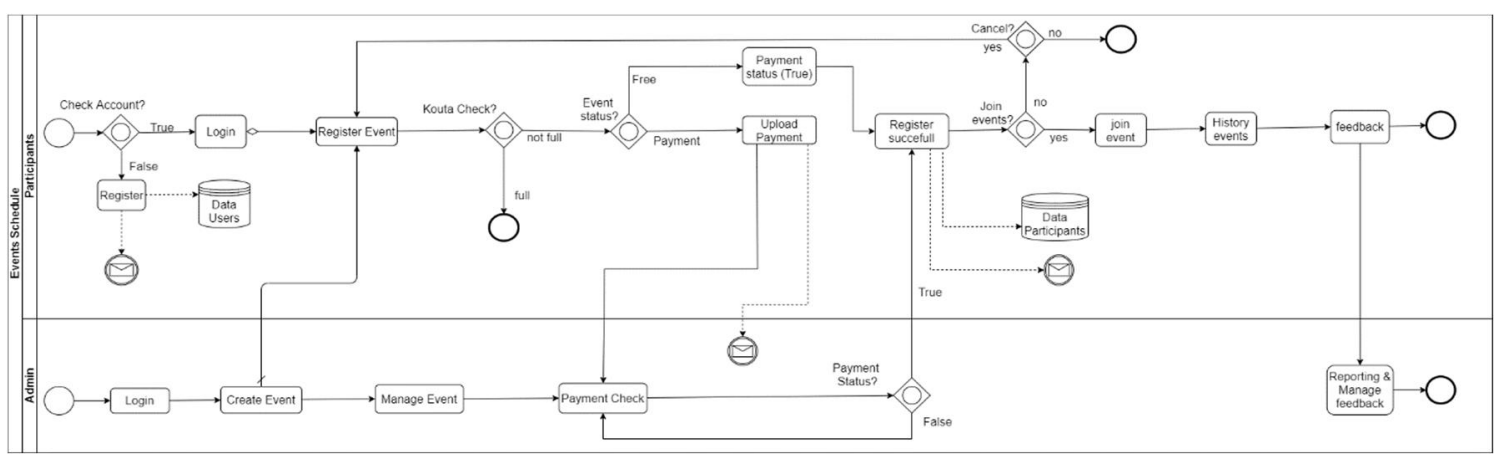

Gambar 2. BPMN Web Event

Gambar 2 Menggambarkan BPMN dari aplikasi web event. Dalam BPMN ini dijelaskan bahwa user harus melakukan login dahulu sebelum registrasi event, jika belum memiliki akun partisipan harus melakukan registrasi akun. Pada registrasi event kita bisa melihat kuota sudah penuh atau belum, jika belum penuh peserta bisa melakukan registrasi. Sistem akan mengecek event yang diikuti itu berbayar atau tidak, jika tidak berbayar maka peserta akan menerima notifikasi email pendaftaran, jika berbayar peserta wajib mengupload bukti pembayaran kemudian admin akan mengkonfirmasi pembayaran baru peserta menerima notifikasi pendaftaran. Pendaftaran event akan masuk di history akun partisipan. Setelah event berakhir partisipan wajib memberi feedback agar mendapatkan sertifikat.

Pada sisi admin, admin harus login terlebih dahulu sebelum memanajemen event. Setelah admin melakukan login admin dapat mendaftarkan atau membuat event baru. Admin dapat mengedit event yang sudah ada maupun yang baru dibuat. Admin dapat mengecek bukti pembayaran dari partisipan jika bukti pembayaran valid makan admin akan mengubah status partisipan dari belum membayar menjadi sudah membayar. Admin juga dapat melihat feedback dari partisipan.

\subsection{Use Case Diagram}

Use Case Diagram berguna untuk menggambarkan interaksi pengguna dengan sistem dan menggambarkan hubungan sistem dengan pengguna. 


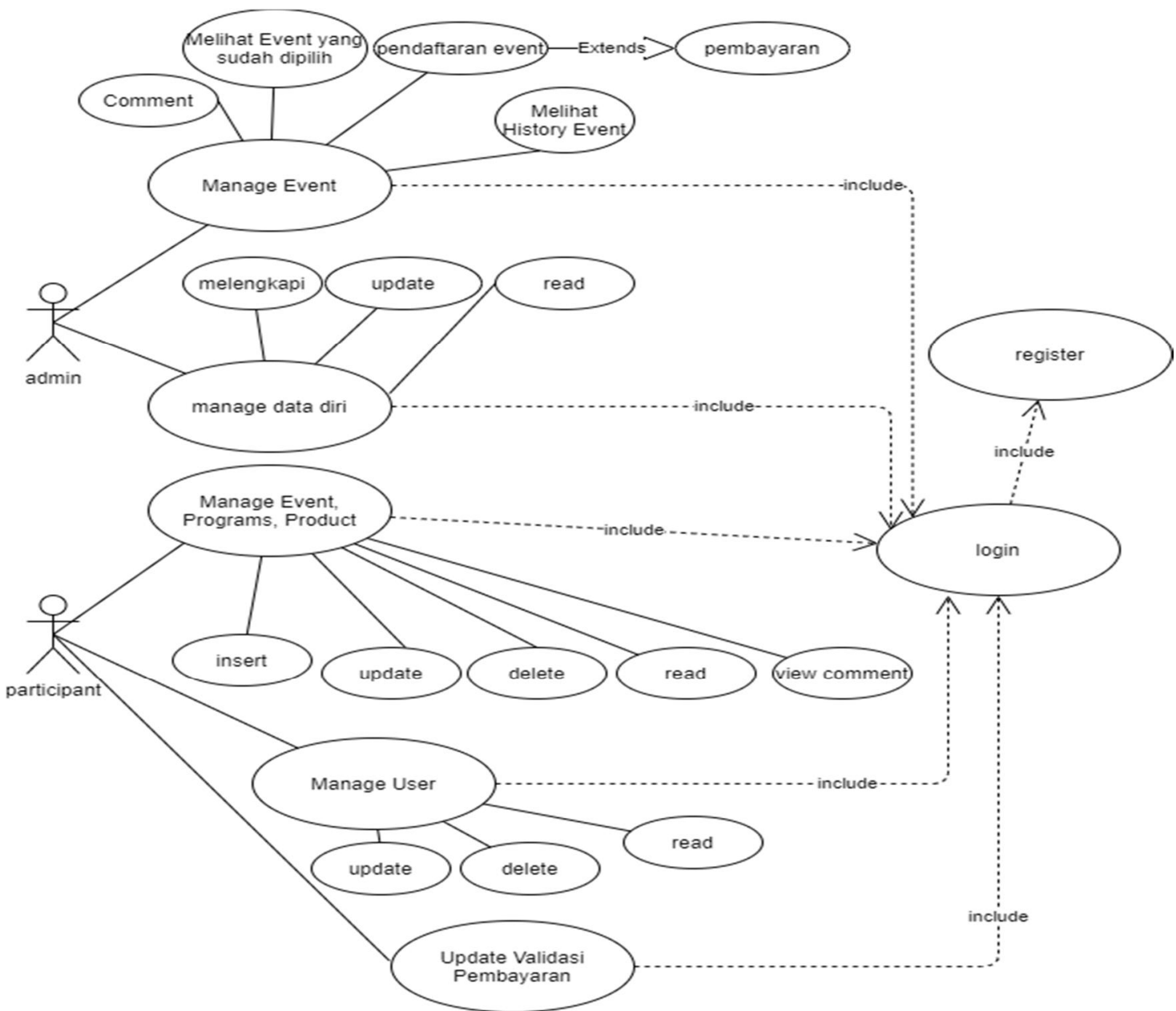

Gambar 3. Use Case Web Event

Gambar 3 menggambarkan Use Case dari aplikasi web event, dalam Use Case ini melibatkan dua aktor yaitu dari sisi admin dan dari sisi participant. Admin memiliki akses untuk mengelola event, program dan produk. Selain itu Admin juga memiliki hak akses mengelola data user dan melakukan update validasi pembayaran yang dilakukan user. Sedangkan pada sisi user dapat mengelola data user, melakukan pendaftaran event dan mendapatkan informasi event yang akan diadakan.

\subsection{Class Diagram}

Class Diagram adalah diagram yang berguna untuk menggambarkan struktur sistem yang berisi sistem kelas, atribut, metode dan hubungan antara objek. 


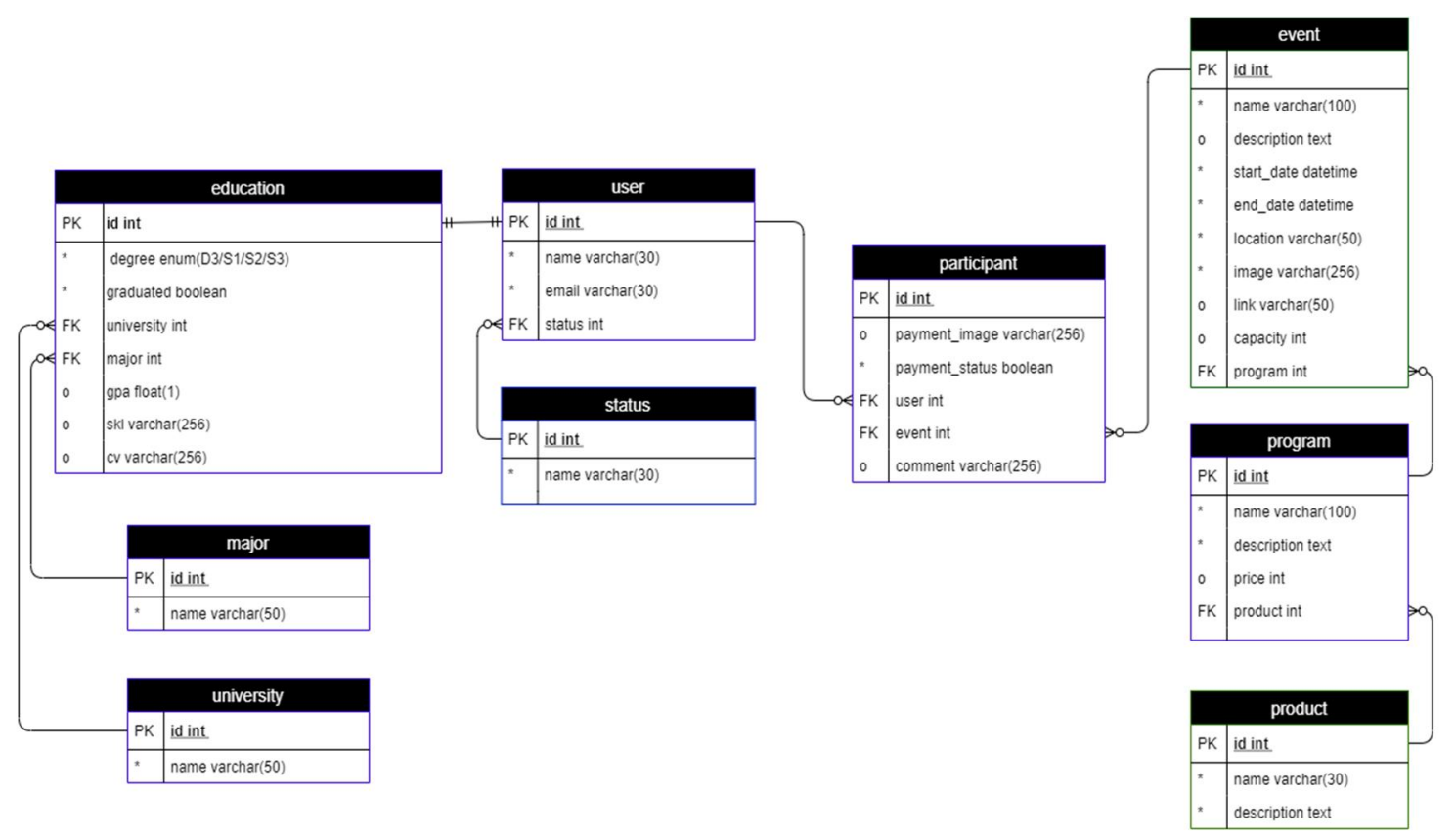

Gambar 4. Class Diagram Web Event

Pada Gambar 4 merupakan Class Diagram pada aplikasi web event. Dalam perancangan Class Diagram menghasilkan sembilan kelas yang memiliki attribute serta kardinalitasnya masing-masing.

\subsection{Configuration Application Properties}

Tahap awal pembuatan project Spring Boot yang dilakukan menambahkan dependency sesuai kebutuhan yang akan digunakan. Dependency merupakan salah satu fitur pada Spring Boot yang berguna mempermudah penulisan coding dalam pembanguan aplikasi Spring Boot [11]. Tahap selanjutnya hal yang dilakukan adalah melakukan konfigurasi pada Application Properties. Application Properties pada Spring Boot berisi file konfigurasi yang berisi perintah pengaturan yang akan digunakan pada aplikasi. Berikut gambaran konfigurasi Application Properties yang dilakukan :

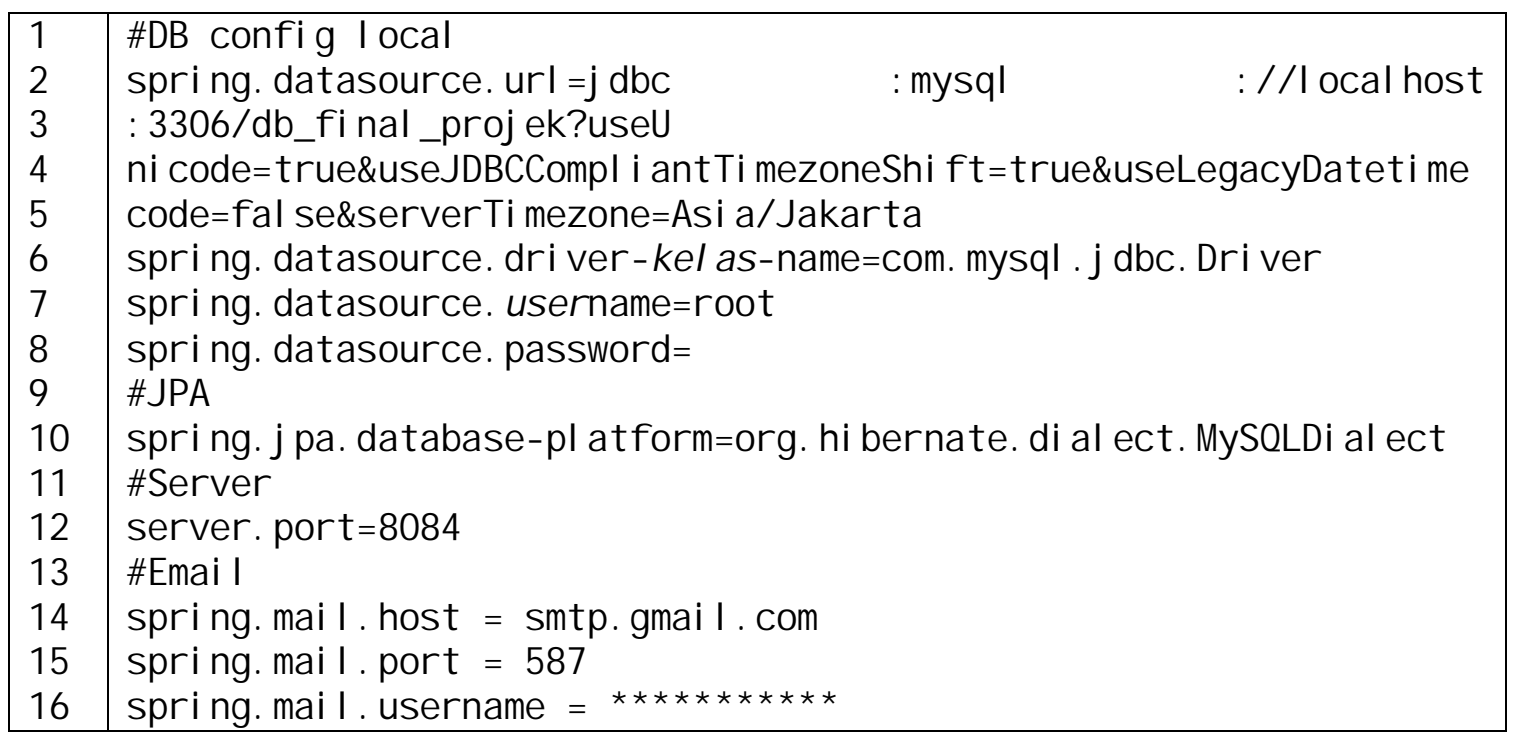




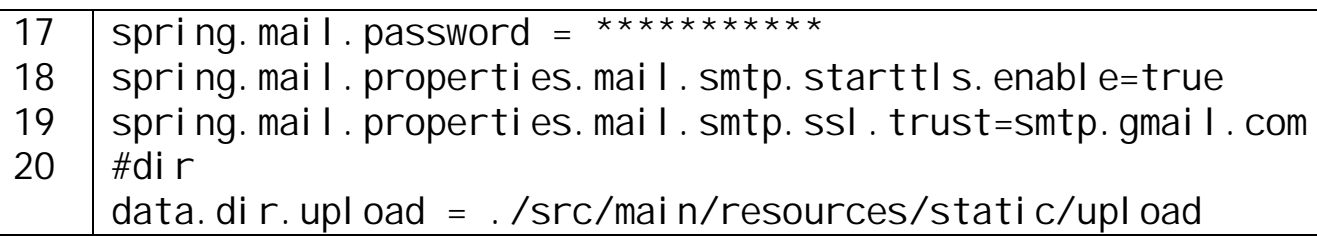

Gambar 5. Konfigurasi Application Properties

Pada Gambar 5 di baris $1-7$ adalah konfigurasi untuk mengakses database local, database yang digunakan pada aplikasi ini adalah database MySQL. Pada baris 9 adalah konfigurasi JPA, JPA sendiri adalah Java Persistence API yang berguna untuk standar spesifikasi cara untuk mengakses database di Java. Pada dibaris 11 menggambarkan konfigurasi pada port mana server akan berjalan jika aplikasi di jalankan. Pada baris 13 - 18 adalah konfigurasi host email yang akan digunakan untuk mengirim email pada fungsi email sender. Konfigurasi pada baris 20 adalah alamat direktori yang akan di gunakan untuk menyimpan hasil upload gambar bukti pebayaran.

\subsection{Pembangunan Program menggunakan Konsep MVC}

Dalam penerapan konsep MVC pada pembangunan aplikasi web event menghasilkan 5 package yaitu Configurations, Controllers, Entities, Services, Repositories yang masing masing memiliki perannya sendiri. Berikut gambar struktur program:

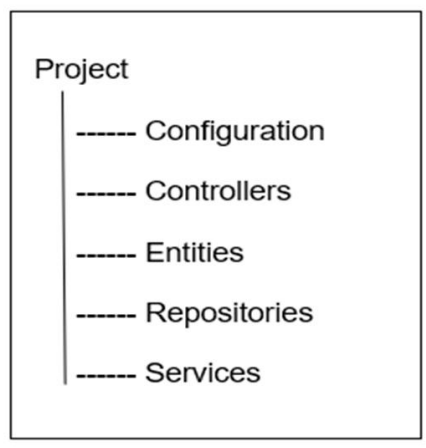

Gambar 6. Struktur MVC

Dalam pengerjaan project langkah awal yang dilakukan adalah membuat kelas pada package Entities. Entities merupakan kelas yang menghubungkan dengan database. Semua kelas yang berada di package Entities merupakan implementasi tabel-tabel dari database yang diakses ke dalam bentuk kelas java. Isi dari Entities ini adalah constructor program, serta setter \& getter serta anotasi-anotasi yang dibutuhkan untuk memanipulasi data. Di dalam kelas ini juga terdapat anotasi @Entity dan @Table sebagai penanda bahwa ini merupakan kelas Entities dan tabel mana merupakan nama tabel yang diakses dari database tersebut. Berikut gambaran dari kelas Entities :

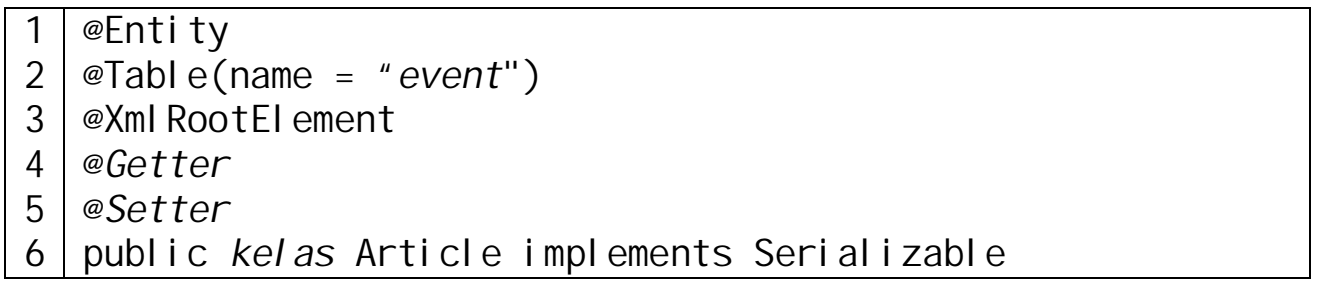

Gambar 7. Kelas Entities 
Pengerjaan kelas Repository dilakukan setelah mengimplementasikan semua tabel dari database ke dalam kelas java. Kelas Repository pada project ini merupakan kelas interface yang berguna untuk menghubungkan kelas Service dengan kelas Entities. Kegunaan yang lain adalah agar implementasi kelas induk bisa digunakan di banyak kelas karena jika tidak menggunakan kelas interface, kelas induk hanya boleh mewariskan fungsinya hanya pada satu anak kelas. Berikut gambaran dari kelas Repository:

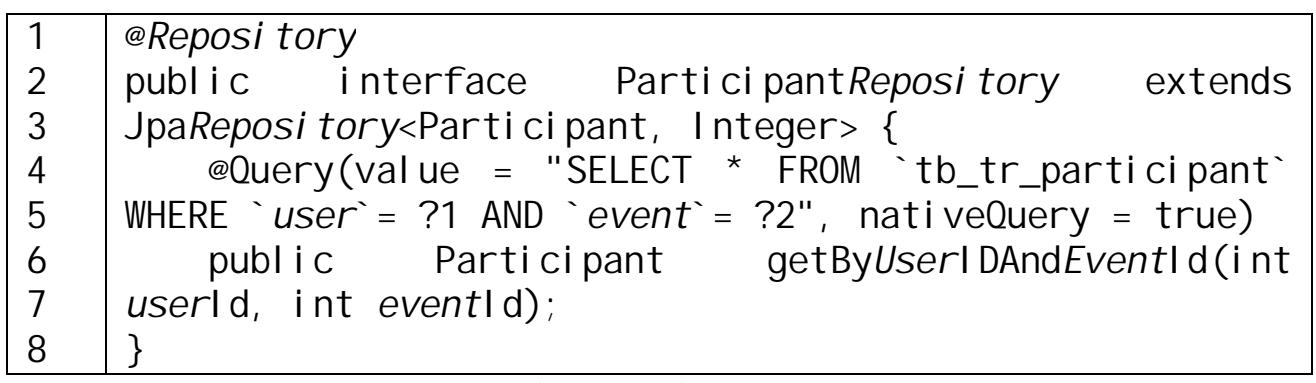

Gambar 8. Kelas Repository

Pada Gambar 8 merupakan salah satu gambaran kelas interface yang digunakan pada project ini. Pada kelas Repository menggunakan JpaRepository untuk mengakses kelas database. JPA sendiri merupakan standar akses database yang digunakan pada bahasa pemrograman Java. JpaRepository sendiri adalah Repository dari Java Persistence API yang memudahkan kita sebagai developer membuat CRUD pada String Data. Pada baris 4 sampai 7 merupakan custom query yang berguna mengecek apakah pendaftar sudah pernah melakukan pendaftaran.

Pembangunan kelas Service dilakukan setelah implementasi kelas interface pada Repository. Pada kelas Service terdapat anotasi @Service untuk memberitahu kepada Spring bahwa ini merupakan sebuah Service. Service sendiri pada project ini berguna untuk membuat fungsi CRUD dan mengolah data dari kelas Entities yang dijembatani kelas interface yang terdapat di kelas Repository. Fungsi - fungsi yang dibuat pada kelas Service sendiri dibuat sesuai kebutuhan dari aplikasi.

Setelah pengerjaan kelas Service selesai hal yang dilakukan adalah mapping yang akan dikerjakan pada kelas Controller. Pada kelas Controller terdapat anotasi @ RestController untuk memberitahu kepada Spring bahwa ini merupakan sebuah kontroler. Pada package Controller bertugas menghubungkan fungsi pada Services ke pengguna atau ke bagian front end dan bertugas merespon inputan dari pengguna dengan melakukan aksi berdasarkan inputan tersebut. Berikut contoh kode fungsi yang ada di Controller:

\begin{tabular}{|l|l|l|}
\hline 1 & QGetMapping("/detail/ $\{$ id $\} ")$ & \\
2 & public String eventDetail(Model model, @PathVariable \\
3 & int id) \{
\end{tabular}

Gambar 9. Kelas Controller

Pada Gambar 9 terdapat anotasi @ GetMapping yang berguna untuk memberitahu kepada program bahwa fungsi ini akan melakukan request Get data kepada server dan @GetMapping juga memetakan path url yang berguna untuk bisa diakses oleh front end.

Untuk menunjang keamanan program, pembangunan aplikasi ini menggunakan sistem keamanan yang sudah disediakan yaitu Spring Security dikarenakan ada beberapa Service yang hanya bisa di akses oleh role admin. Pada package Configurations berisi kelas yang berguna untuk mengkonfigurasi Spring Security. Spring Security sendiri merupakan fitur keamanan pada 
Java Web dengan cara menerapkan hijacking pada HTTP request menggunakan Filter yang mengerjakan pengecekan keamanan.

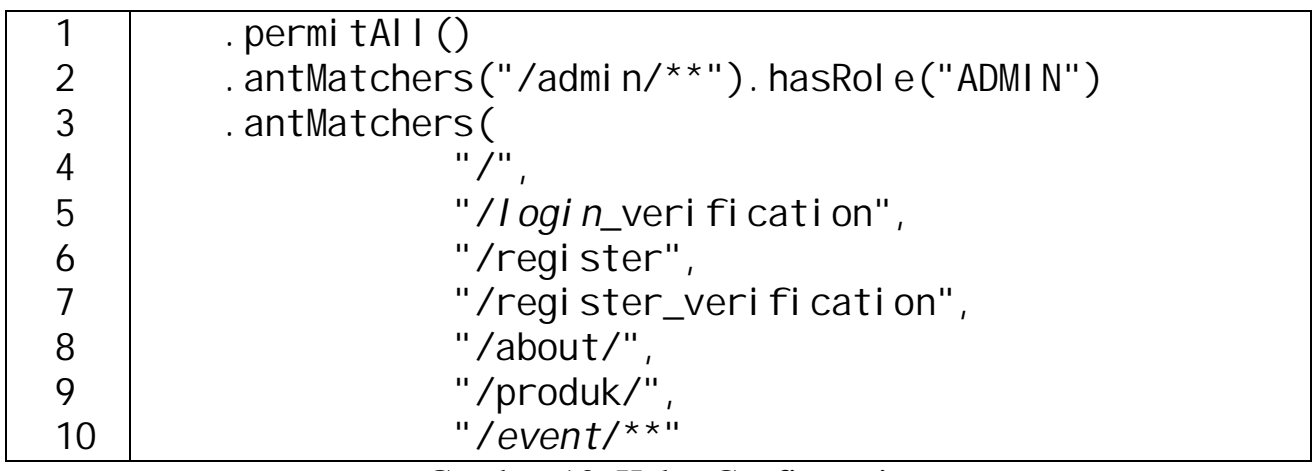

Gambar 10. Kelas Configuration

Pada Gambar 10 adalah Configuration user yang memiliki role admin, kode pada baris 4 sampai 10 menjelaskan halaman yang bisa di akses oleh admin.

\subsection{Pembangunan Interface}

Pembangunan interface pada aplikasi web event sendiri menggunakan html, javascript dan menggunakan CSS Bootstrap untuk mempercantik tampilan. Pembangunan interface juga menggunakan Thymeleaf yang merupakan moderen template engine yang support dengan html 5. Thymeleaf merupakan Serverside Java Template Engine yang diperuntukan untuk membangun sebuah Aplikasi Web dan Thymeleaf sendiri sudah terintegrasi dengan Framework Spring Boot. Berikut gambaran singkat implementasi Thymeleaf:

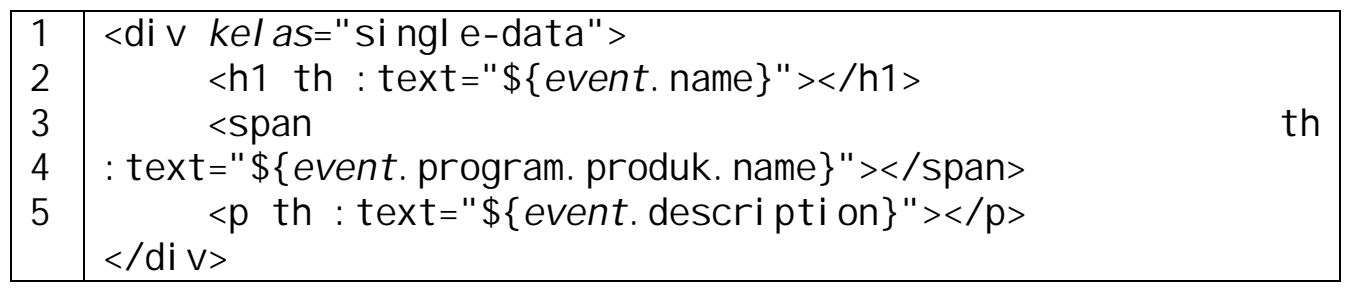

Gambar 11. Penggunaan Thymeleaf

Pada Gambar 11 merupakan contoh penerapan Thymeleaf untuk menangkap data dari fungsi yang ada pada Controller dan memunculkan data berupa nama event, nama produknya dan deskripsi event pada halaman web. Berikut adalah beberapa tampilan web dari hasil penerapan dari html, Bootstrap, javascript dan Thymeleaf : 


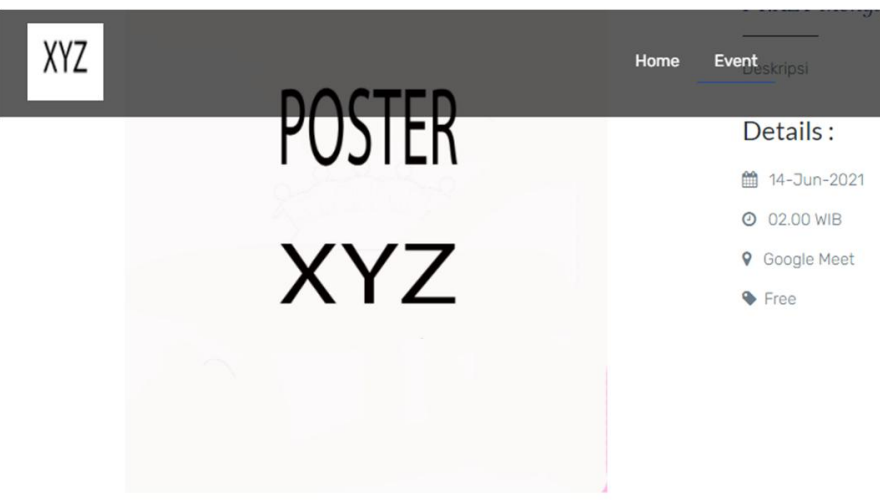

Pada halam registrasi event hanya bisa diakses user yang sudah melakukan login. Untuk melakukan registrasi tinggal menekan tombol registrasi now.

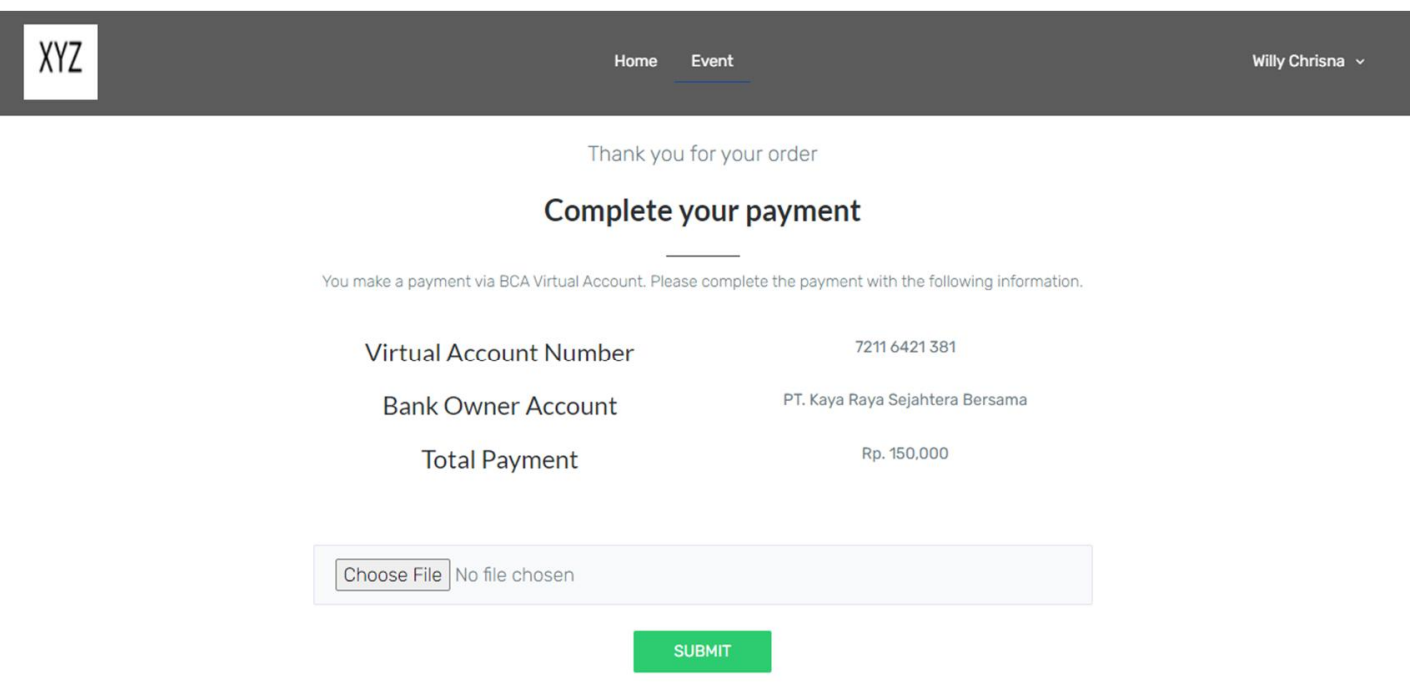

Gambar 13. Tampilan Halaman Payment

Pada halaman ini user diminta mengupload bukti pembayaran event, setelah user mengupload bukti pembayaran dari sistem akan otomatis mengirim email ke admin untuk segera mengkonfirmasi pembayaran.

\subsection{Testing}

Metode testing yang digunakan pada penelitian ini adalah menggunakan metode Black Box berikut beberapa hasil dari testing yang dilakukan: 
1. Pengujian Login

\begin{tabular}{|c|c|c|c|}
\hline Pengujian & $\begin{array}{c}\text { Hasil Yang } \\
\text { Diharapkan }\end{array}$ & $\begin{array}{c}\text { Hasil } \\
\text { Pengujian }\end{array}$ & Kesimpulan \\
\hline Memasukan & Proses & Proses & Sukses \\
Username & berhasil & berhasil & \\
dan & dengan login & & \\
Password & menggunakan & & \\
yang sudah & username dan & & \\
terdaftar & password & & \\
& yang sudah & & \\
& terdaftar & & \\
\hline
\end{tabular}

\section{Pengujian Mendaftar Event}

\begin{tabular}{|c|c|c|c|}
\hline Pengujian & $\begin{array}{c}\text { Hasil Yang } \\
\text { Diharapkan }\end{array}$ & $\begin{array}{c}\text { Hasil } \\
\text { Pengujian }\end{array}$ & Kesimpulan \\
\hline Melakukan & $\begin{array}{c}\text { Pendaftaran } \\
\text { berhasil } \\
\text { pendaftaran } \\
\text { event yang } \\
\text { berbayar } \\
\text { dengan } \\
\text { peroses }\end{array}$ & Sukses \\
pendaftar & & \\
berbayar & $\begin{array}{c}\text { menerima } \\
\text { email } \\
\text { konfirmasi }\end{array}$ & & \\
& & \\
pedaftaran & & \\
\hline
\end{tabular}

3. Pengujian Transaksi

\begin{tabular}{|c|c|c|c|}
\hline Pengujian & $\begin{array}{c}\text { Hasil Yang } \\
\text { Diharapkan }\end{array}$ & $\begin{array}{c}\text { Hasil } \\
\text { Pengujian }\end{array}$ & Kesimpulan \\
\hline Memasukan & Proses & Proses & Sukses \\
foto bukti & berhasil & berhasil & \\
pembayaran & dan data & & \\
& transaksi & & \\
& berhasil & & \\
& disimpan & & \\
& di database & & \\
\hline
\end{tabular}

\subsection{Maintenance}

Perbaikan dan pemeliharaan sistem akan dilakukan jika tedapata update sistem atau ditemukannya kesalahan pada sistem pada saat digunakan oleh user.

\section{KESIMPULAN}

Berdasarkan penelitian yang dilakukan dapat disimpulkan bahwa pembangunan aplikasi web menggunakan Spring Boot sangat mudah karena didukung dengan library yang lengkap dan Spring Boot sangat ringan saat digunakan.

Dengan adanya aplikasi web event sangat membantu user dalam melakukan pendaftaran event karena menggunakan sistem sehingga tidak manual lagi dan dimudahkan dengan fitur fitur yang tersedia. Pada sisi admin dimudahkan dalam mengatur event yang akan diadakan dan event yang akan berlangsung. 


\section{SARAN}

Saran yang ingin disampaikan penullis adalah untuk yang diperlukan oleh sistem ini adalah melakukan pengembangan lebih lanjut dibagian fitur program agar bisa memenuhi kebutuhan user dan pengembagan lebih lanjut dibagian interface agar lebih menarik lagi.

\section{DAFTAR PUSTAKA}

[1] Natsir Mohamad. 2016, Pengembangan Prototype Sistem Kriptografi Untuk Enkripsi dan Dekripsi Data Office Menggunakan Metode Blowfish Dengan Bahasa Pemrograman Java, Jurnal Format Volume 6 nomor 2 Tahun 2016: ISSN: 2089 -5615, Jakarta.

[2] Sibarani, Niko Sumanda., Munawa, Ghifari., Wisnuadh, Bambang. 2018. Analisis Performa Aplikasi Android pada Bahasa Pemrograman Java dan Kotlin, Vol 9 2018, Industrial Research Workshop and National Seminar.

[3] Sallaby, Achmad Fikri., Feri, Hari, Utami., Yode, Arliando. 2015. Aplikasi Widget Berbasis Java. Jurnal Media Infotama Vol. 11 No. 2, September 2015

[4] Toha, M. 2010, Implementasi Framework Spring Mvc Untuk Pembuatan Sistem Informasi Manajemen E Commerce

[5] Kurniawan Yosua., Yerymia Alfa Susetyo. 2020, Perancangan Sistem Asset Management Berbasis Web Menggunakan Framework Spring Boot (Studi Kasus: PT XYZ), Fakultas Teknologi Informasi Universitas Kristen Satya Wacana.

[6] Jovanović, Željko., Jagodić, Dijana., Vujičić, Dejan., Ranđić, Siniša. 2017, Java Spring Boot Rest Web Service Integration with Java Artificial Intelligence Weka Framework. Gabrovo: International Scientific Conference

[7] Ilman, Benie., Ginanjar, Arief. 2018. Rancang Bangun Web Service - JSON Menggunakan Kombinasi Spring dan MyBatis Framework Dalam Lingkungan Java Platform, Program Studi Informatika Universitas Langlangbuana

[8] Simanjuntak, Pastima., Kasnady Arwin. 2016, Analisis Model View Controller (Mvc) pada Bahasa Php, Jurnal ISD Vol.2 No.2 Juli - Desember 2016 e-ISSN: 2528-5114

[9] Bachri, Hendro Febrian., Priyambadha, Bayu. Rusdianto, Denny Sagita. 2018, Pengembangan Aplikasi Manajemen Event Berbasis Web (Studi Kasus: Fakultas Ilmu Administrasi Universitas Brawijaya Malang), Jurnal Pengembangan Teknologi Informasi dan Ilmu Komputer Vol. 2, No. 12, Desember 2018, hlm. 6752-6760

[10] Ismanto., Firman Hidayah., Kristinanti. 2020, Pemodelan Proses Bisnis Menggunakan Business Process Modelling Notation (BPMN) (Studi Kasus Unit Penelitian dan Pengabdian Kepada Masyarakat (P2KM) Akademi Komunitas Negeri Putra Sang Fajar Blitar), BRILIANT: Jurnal Riset dan Konseptual Volume 5 Nomor 1

[11] spring.io, "Building an Application with Spring Boot". 25 Mei 2021, < http ://www.spring.io> 